\title{
TU/e EN⿴HONE

\section{Decay of the electron density and the electron collision frequency between successive discharges of a pulsed plasma jet in N2}

Citation for published version (APA):

van der Schans, M., Platier, B., Koelman, P., van de Wetering, F. M. J. H., van Dijk, J., Beckers, J., Nijdam, S., \& IJzerman, W. (2019). Decay of the electron density and the electron collision frequency between successive discharges of a pulsed plasma jet in $\mathrm{N}_{2}$. Plasma Sources Science and Technology, 28(3), [035020]. https://doi.org/10.1088/1361-6595/ab096e

\section{Document license:}

TAVERNE

DOI:

10.1088/1361-6595/ab096e

Document status and date:

Published: 27/03/2019

\section{Document Version:}

Publisher's PDF, also known as Version of Record (includes final page, issue and volume numbers)

\section{Please check the document version of this publication:}

- A submitted manuscript is the version of the article upon submission and before peer-review. There can be important differences between the submitted version and the official published version of record. People interested in the research are advised to contact the author for the final version of the publication, or visit the $\mathrm{DOI}$ to the publisher's website.

- The final author version and the galley proof are versions of the publication after peer review.

- The final published version features the final layout of the paper including the volume, issue and page numbers.

Link to publication

\footnotetext{
General rights

- You may freely distribute the URL identifying the publication in the public portal. follow below link for the End User Agreement:

www.tue.nl/taverne

\section{Take down policy}

If you believe that this document breaches copyright please contact us at:

openaccess@tue.nl

providing details and we will investigate your claim.
}

Copyright and moral rights for the publications made accessible in the public portal are retained by the authors and/or other copyright owners and it is a condition of accessing publications that users recognise and abide by the legal requirements associated with these rights.

- Users may download and print one copy of any publication from the public portal for the purpose of private study or research.

- You may not further distribute the material or use it for any profit-making activity or commercial gain

If the publication is distributed under the terms of Article 25fa of the Dutch Copyright Act, indicated by the "Taverne" license above, please 


\section{PAPER}

Decay of the electron density and the electron collision frequency between successive discharges of a pulsed plasma jet in $\mathrm{N}_{2}$

To cite this article: Marc van der Schans et al 2019 Plasma Sources Sci. Technol. 28035020

View the article online for updates and enhancements.

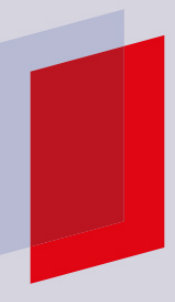

\section{IOP ebooks}

Bringing you innovative digital publishing with leading voices

to create your essential collection of books in STEM research.

Start exploring the collection - download the first chapter of every title for free. 


\title{
Decay of the electron density and the electron collision frequency between successive discharges of a pulsed plasma jet in $\mathrm{N}_{2}$
}

\author{
Marc van der Schans ${ }^{1,4}{ }^{\infty}$, Bart Platier ${ }^{1,4}$, Peter Koelman ${ }^{1}{ }^{\oplus}$, \\ Ferdi van de Wetering ${ }^{1}$, Jan van Dijk ${ }^{1}$, Job Beckers ${ }^{1}{ }^{10}$, \\ Sander Nijdam ${ }^{1}$ (i) and Wilbert IJzerman ${ }^{2,3}$ \\ ${ }^{1}$ Department of Applied Physics, Eindhoven University of Technology, PO Box 513, 5600MB Eindhoven, \\ The Netherlands \\ ${ }^{2}$ Department of Mathematics and Computer Science, Eindhoven University of Technology, PO Box 513, \\ 5600MB Eindhoven, The Netherlands \\ ${ }^{3}$ Signify, High Tech Campus 7, 5656 AE Eindhoven, The Netherlands \\ E-mail: m.van.der.schans@tue.nl and b.platier@tue.nl
}

Received 17 December 2018, revised 28 January 2019

Accepted for publication 22 February 2019

Published 27 March 2019

\begin{abstract}
The decay of the electron density and electron collision frequency between successive discharges in a pulsed plasma jet in $\mathrm{N}_{2}$ feed gas has been investigated using microwave cavity resonance spectroscopy. The method and analysis were adapted to be able to apply this diagnostic to a pulsed plasma jet at atmospheric pressure. The results are compared to a global model. It is shown that the electron density and effective collision frequency can be measured using this technique from about $1 \mu \mathrm{s}$ up to approximately $60 \mu \mathrm{s}$ after the discharge, where the former time scale is limited by the response time of the cavity and the latter by the detection limit of the setup. Although the data analysis requires an estimation of the plasma volume, which limits the absolute accuracy of the electron density to its order of magnitude, the measured electron densities are in the same range as those predicted by the global model. Additionally, there is a good qualitative agreement in the electron density decay rate between the measurements and the model. Furthermore, it is inferred from the model that the minimum seed electron density required for repeatable guided streamer discharges in a pulsed plasma jet in $\mathrm{N}_{2}$ feed gas is of the order of $10^{15} \mathrm{~m}^{-3}$
\end{abstract}

Keywords: atmospheric pressure plasma jet, plasma bullet, guided streamer, electron density, collision frequency, microwave cavity resonance spectroscopy

\section{Introduction}

Atmospheric pressure plasma jets (APPJs) are discharges generated in a flow of gas at atmospheric pressure [1-3]. APPJs have been, and continue to be, investigated for various industrial applications, which include surface cleaning and coating [4], thin film deposition [5], and photoresist removal

\footnotetext{
${ }^{4}$ The authors to whom correspondence should be addressed
}

[6], as well as for applications in plasma medicine [7], such as cancer treatment [8].

When an APPJ is driven by repeatedly pulsed voltage with a kHz-range repetition frequency, typically highly reproducible guided streamer discharges (often named 'plasma bullets' or 'guided ionisation waves') are generated $[1,9-12]$. Thanks to their reproducibility, guided streamer discharges in pulsed plasma jets are a useful tool for investigating streamer physics. The guided streamers in pulsed plasma jets are reproducible by virtue of a memory effect: 
remnants of previous discharges provide the seed electrons for the next discharge [12]. Since seed electrons mediate the memory effect, knowledge of the electron density, as well as its evolution between successive discharges, is essential in understanding the physics of pulsed plasma jets and the memory effect. However, since the electron density decays exponentially between successive discharges, it is challenging to directly measure the electron density experimentally.

Various diagnostics exist to measure the electron density in APPJs. For example, electron densities can be determined from Stark broadening of spectral lines measured using optical emission spectroscopy [13]. However, this technique is inherently limited to times when light is emitted by the plasma during a discharge. Thomson scattering, the scattering of laser light on free electrons, has also been used before to measure the electron densities in radio-frequency and microwave excited APPJs [14-16], as well as in pulsed plasma jets in He and Ar during or briefly after the discharge [17-19]. With Thomson scattering both high temporal and spatial resolution can be achieved when tightly focused, short laser pulses are used. However, the detection limit of this technique at atmospheric pressure is usually of the order of $10^{18} \mathrm{~m}^{-3}$ for pure Thomson scattering and is higher when simultaneous rotational Raman scattering occurs [14], such as in $\mathrm{N}_{2}$. This is too high to measure the evolution of electron densities between consecutive discharges.

Several microwave techniques are also used for electron density measurements. For example, millimetre interferometry [20, 21] and microwave scattering [22] have recently been used to measure the evolution of electron density in pulsed discharges at atmospheric pressure. Another microwave technique, which will be used in this work, is microwave cavity resonance spectroscopy (MCRS). This diagnostic has been applied to a variety of low-pressure plasmas over the years [23-31]. Compared to Thomson scattering, MCRS is capable of measuring lower electron densities. The temporal resolution depends on the quality factor and the resulting response time of the used cavity. Typically cavities with a temporal resolution of the order of tens of ns to a $\mu \mathrm{s}$ are used. Furthermore, plasma properties obtained from MCRS are averaged over the cavity volume and are hence not spatially resolved. Nevertheless, with prior knowledge on the approximate electron density distribution, MCRS is potentially a suitable diagnostic for the electron densities in the time between successive discharges where $\mu \mathrm{s}$ resolution suffices. Additionally, it should also be noted that multi-mode MCRS, in which multiple cavity modes are used to reconstruct the spatial distribution of the electron density, was recently reported [32].

In MCRS, a microwave cavity is placed around the plasma. The resonances of the cavity depend on the properties of the medium inside the cavity. Therefore, introducing a discharge in the cavity can change the resonance frequency as well as the quality factor of the cavity. Usually, cavity perturbation theory is used to relate changes in resonance behaviour to properties of the plasma. For low-pressure plasmas, where the electron-neutral collision frequency is negligible compared to the resonant microwave frequency, the electron density can be determined directly from the shift in resonance frequency [23]. However, the effects of electronneutral collisions cannot be neglected at higher pressures. This makes the relation between the resonance properties of the cavity and the plasma properties more complex. In this case, a more intricate analysis is required, in which not only the shift in resonance frequency but also the change in quality factor has to be considered. The advantage, though, is that such an analysis also results in information on the collision frequency, in addition to the electron density.

In this work, MCRS is adapted for APPJs and applied to a pulsed plasma jet in $\mathrm{N}_{2}$ feed gas flowing into ambient air. The required analysis is developed and used to determine the temporal behaviour of the electron density and collision frequency between successive discharges. In addition, the experimental results are compared to those predicted by a global model.

\section{Experimental setup and methods}

\subsection{Setup and measurement system}

The experimental setup is schematically illustrated in figure 1 . The plasma source itself is the same as in [33] and will only be explained here briefly. A pulsed plasma jet is generated in $\mathrm{N}_{2}$ feed gas (purity of $99.999 \%$ ) flowing at a volumetric rate of $1 \mathrm{slm}$. A high voltage (HV) power supply (Spellman SL10PN60) provides a DC voltage to a HV pulse generator (DEI PVX-4110). The latter is gated by a pulse/delay generator (BNC model 575) in order to generate voltage pulses with a width of $500 \mathrm{~ns}$ and rise and fall times of about $40 \mathrm{~ns}$. The HV pulses are applied to a needle electrode that has a radius of $0.5 \mathrm{~mm}$ and a tip angle of approximately $20^{\circ}$. The needle electrode is placed concentrically inside a quartz tube of inner radius $1 \mathrm{~mm}$ and outer radius $2 \mathrm{~mm}$, with the tip of the needle located $2 \mathrm{~mm}$ before the end of the quartz tube. At the rising edge of every voltage pulse, a guided streamer is generated that propagates from the tip of the needle along the symmetry axis of the jet and has a radius of approximately $150 \mu \mathrm{m}$. The applied voltage is varied between 4 and $8 \mathrm{kV}$, and a repetition frequency between 2 and $6 \mathrm{kHz}$ is used.

A cylindrical microwave cavity of inner dimensions $\varnothing 66 \times 16 \mathrm{~mm}$ is placed concentrically to the jet. The two flat walls of the cavity have a thickness of $5 \mathrm{~mm}$, and the curved wall has a thickness of $3 \mathrm{~mm}$. The outer surface of the cavity is located at the same axial position as the end of the quartz tube (also see figure 5). The cavity has a hole of $13 \mathrm{~mm}$ diameter in the centre of each of its two flat walls to allow the gas flow and discharge to enter and exit the cavity. A microwave generator (Stanford Research Systems SG386) generates a microwave signal with frequency $f=\omega / 2 \pi$ and power $P_{\text {in }}$. The microwaves travel through a directional coupler (Mini-Circuits ZHDC-10-63-S+), a device that discriminates forward and reverse travelling waves, and are applied to an antenna that protrudes a few $\mathrm{mm}$ into the 


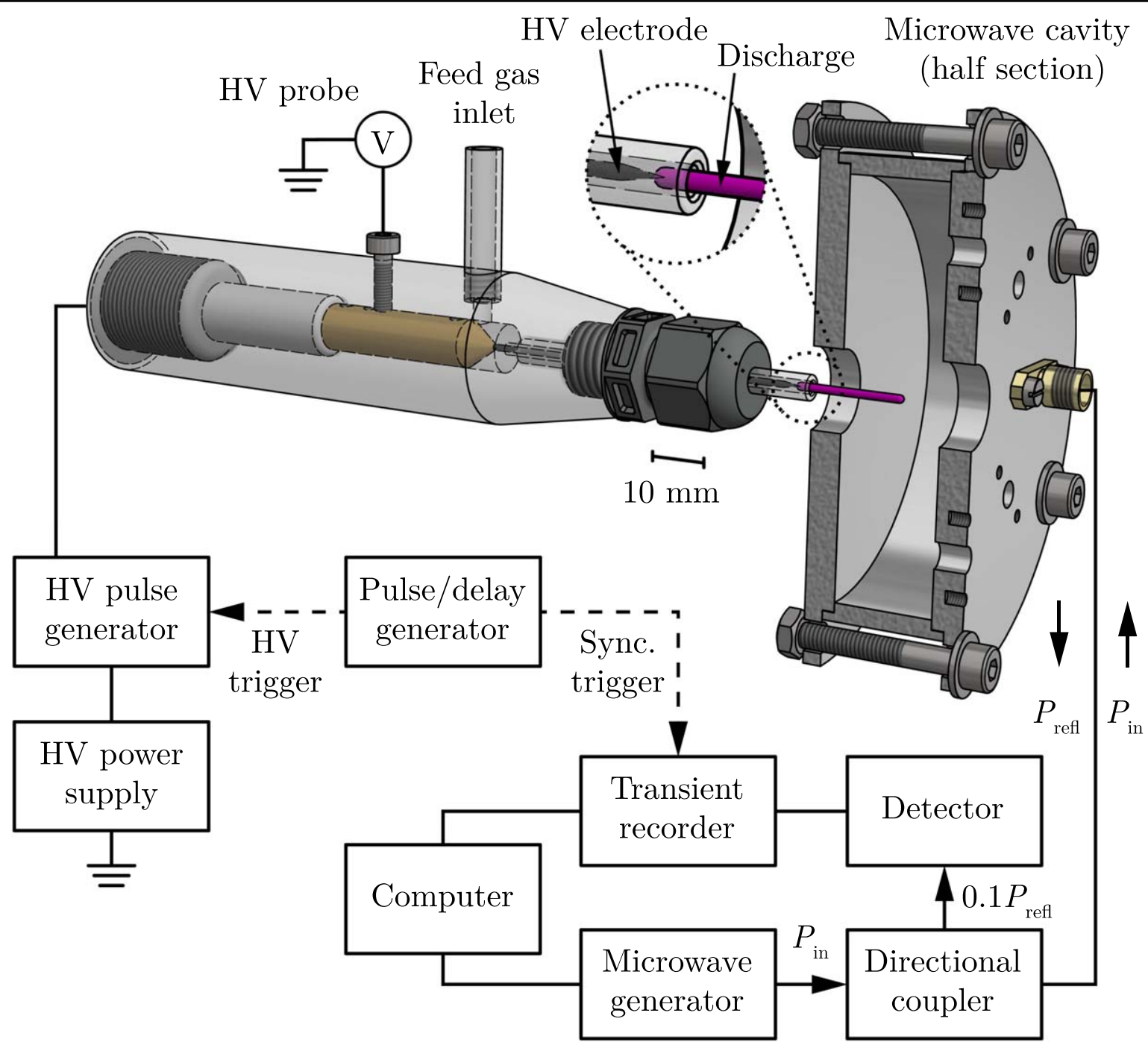

Figure 1. Schematic illustration of the setup. For clarity, only half of the microwave cavity is drawn, and a magnified view of the nozzle is included.

microwave cavity. Depending on the applied frequency, a certain part of the input power is reflected. When the applied frequency matches a resonance frequency of the cavity, the reflected power is minimal. The reflected microwave signal with power $P_{\text {refl }}$ returns to the directional coupler and $10 \%$ of this power is measured by a logarithmic detector (Hittite 602LP4E). This measurement is sampled by a transient recorder (Spectrum M3i.4121-exp) with a sampling frequency of $100 \mathrm{MHz}$. The HV pulse generator of the plasma source and the transient recorder are triggered by the same pulse/ delay generator. The transient recorder data of a time range covering slightly over one entire period of the pulsed voltage is saved to a computer. Since the discharges are reproducible, multiple measurements can be averaged, and the temporal evolution of the plasma properties between discharges can be measured this way. Scanning of the applied frequency and saving of the transient recorder data is automated using a computer program.

A scan of the full frequency range of the microwave generator for an 'empty' cavity, i.e. without a discharge, is shown in figure 2. This reveals two resonances in the available frequency range: the $\mathrm{TM}_{010}$ mode around $3.51 \mathrm{GHz}$ and the $\mathrm{TM}_{110}$ mode around $5.45 \mathrm{GHz}$. The identification of these modes has been confirmed by a COMSOL model of the cavity. However, it is found that the $\mathrm{TM}_{110}$ peak is not prominent enough compared to the background to obtain accurate results from the fitting procedure, which will be explained shortly. Therefore, only the $\mathrm{TM}_{010}$ mode will be used in this work. For the actual measurements, a smaller frequency band of $10 \mathrm{MHz}$ around $3.51 \mathrm{GHz}$ is scanned at $50 \mathrm{kHz}$ intervals. Such a measurement of the $\mathrm{TM}_{010}$ mode for the empty cavity is shown in figure 3. For each of the shown points, 128 measurements are averaged. The standard deviation for each of the data points is approximately $0.01 \mu \mathrm{W}$.

For an ideal lossless cavity, the resonance peak would be a delta peak. In reality, however, there is a band around the resonance frequency $\omega_{0}$ that can lead to substantial excitation of the cavity mode. This is caused by the finite conductivity of the cavity material, as well as potential (ohmic) losses in the medium inside the cavity. The spectral power distribution $P(\omega)$ of a resonance peak around $\omega_{0}$ is Lorentzian and is given 


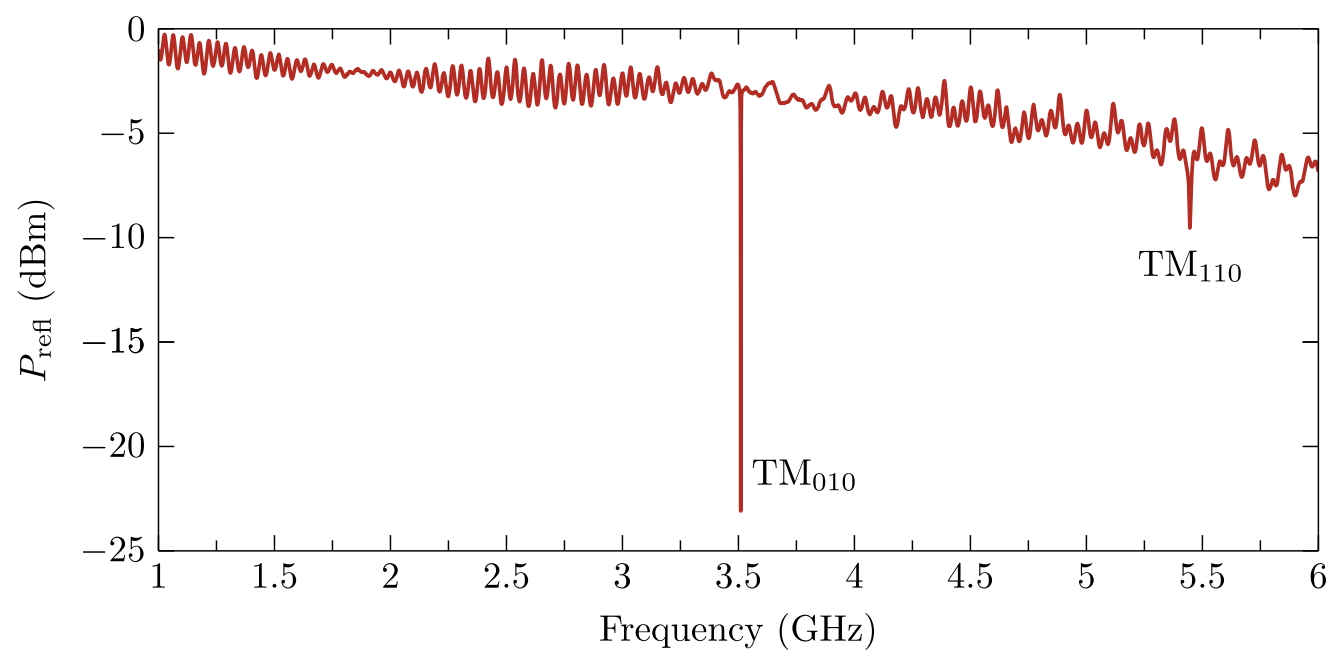

Figure 2. Full frequency range scan of the reflected power with an empty cavity. Two minima and their corresponding cavity modes are indicated.

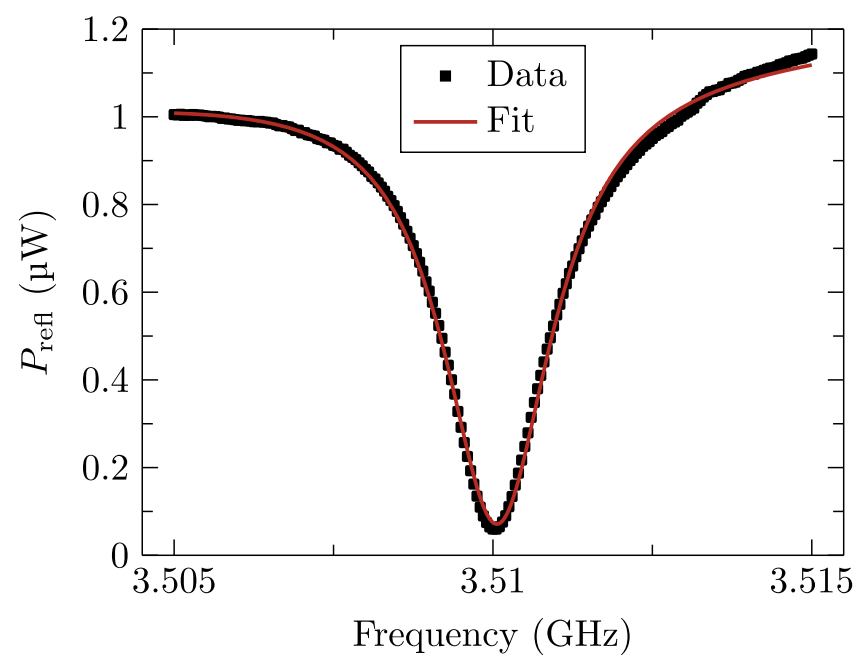

Figure 3. Resonance peak of the $\mathrm{TM}_{010}$ mode in the empty cavity (black marks) and a fit (red line).

by [34]

$$
P(\omega) \propto\left[\left(\omega-\omega_{0}\right)^{2}+\left(\frac{\omega_{0}}{2 Q}\right)^{2}\right]^{-1},
$$

where $Q$ is the so-called quality factor of the cavity mode. The quality factor is related to power losses and determines the width of the resonance peak. It is also directly related to characteristic decay time $\tau=2 Q / \omega_{0}=Q / \pi f_{0}$ of fields in the cavity. The cavity mode can adjust to any changes on the time scale of several $\tau$. Therefore, the characteristic time $\tau$ is also a measure for the temporal resolution of the measurements.

When a plasma is introduced in the cavity, the resonance frequency shifts and the quality factor changes. How these changes relate to the properties of the plasma is explained in the next section. To obtain the frequency shift and the quality factor from the measurements, the resonance peak is fitted using the spectral power distribution. This is done in two steps: firstly, the undisturbed resonance frequency $f_{1}$ and quality factor $Q_{1}$ are determined for an empty cavity using the fit function

$$
\begin{aligned}
& L_{\text {fit }}^{\text {empty }}(f ; \underbrace{f_{1}, Q_{1}, A, a_{0}, a_{1}}_{\text {fit variables }}) \\
& =A \frac{\left(\frac{f_{1}}{2 Q_{1}}\right)^{2}}{\left(f-f_{1}\right)^{2}+\left(\frac{f_{1}}{2 Q_{1}}\right)^{2}}+a_{0}+a_{1}\left(f-f_{1}\right),
\end{aligned}
$$

where the last two terms are added to account for a linear baseline, and $A, a_{0}$ and $a_{1}$ are scaling factors. A fit for the empty cavity using (2) was already included in figure 3 . The resonance frequency and quality factor of the empty cavity are $f_{1}=3.51 \mathrm{GHz}$ and $Q_{1}=1900$ respectively. This means that the characteristic decay time of the system is $\tau \approx 0.2 \mu \mathrm{s}$ and that the temporal resolution is about $1 \mu \mathrm{s}$. Secondly, the frequency shift $\Delta f$ and quality factor $Q_{2}$ in the measurements with a discharge are determined using the fit function

$$
\begin{aligned}
& L_{\text {fit }}(f ; \underbrace{\Delta f, Q_{2}}_{\text {fit variables }}) \\
& \quad=A \frac{\left(\frac{f_{1}}{2 Q_{2}}\right)^{2}}{\left(f-f_{1}-\Delta f\right)^{2}+\left(\frac{f_{1}}{2 Q_{2}}\right)^{2}}+a_{0}+a_{1}\left(f-f_{1}\right),
\end{aligned}
$$

where the values for $f_{1}, A, a_{0}$ and $a_{1}$ obtained from the first fit are used as constants.

As mentioned before, the transient recorder data is saved for a time range covering slightly over one entire period of the pulsed voltage. Examples of the resonance frequency shift $\Delta f$, relative frequency shift $\Delta f / f_{1}$, quality factor $Q_{2}$, and change in reciprocal quality factor $\Delta(1 / Q)=1 / Q_{2}-1 / Q_{1}$ as functions of time are given in figure 4 for an applied voltage of $6 \mathrm{kV}$ and a pulse repetition frequency of $3 \mathrm{kHz}$. In the first $500 \mathrm{~ns}$ after the start of the $\mathrm{HV}$ pulses at $t=0$ and at about $t=333 \mu \mathrm{s}$, some large oscillations are present in the signals. This is most clearly visible in figures 4(a) and (c). This time range corresponds to the duration of the HV pulse, and these artefacts are caused 

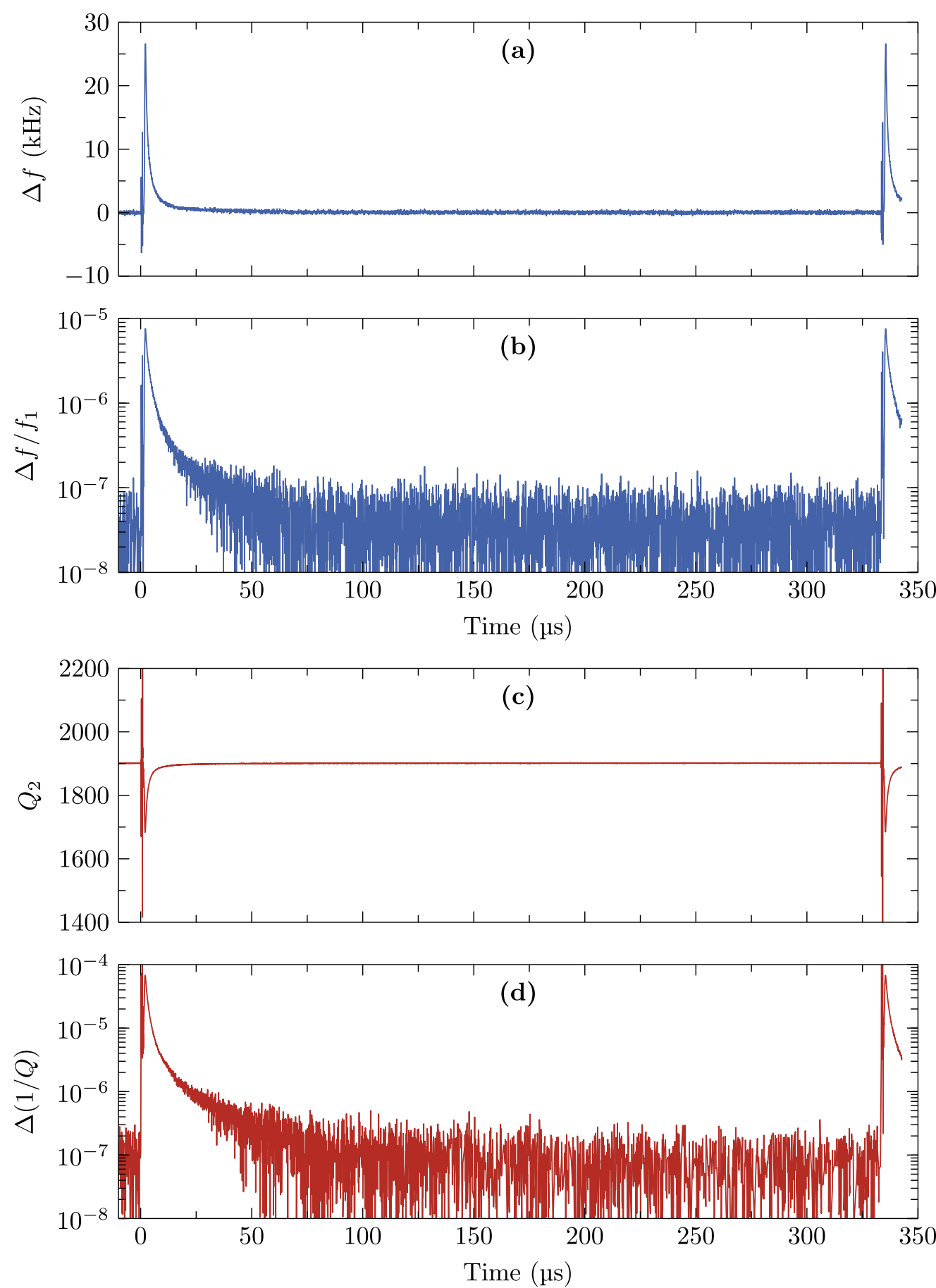

Figure 4. Measurements of (a) the resonance frequency shift, (b) the relative frequency shift, (c) the quality factor, and (d) the change in reciprocal quality factor, as a function of time for discharges at $6 \mathrm{kV}$ and a repetition rate of $3 \mathrm{kHz}$.

by interference. For this reason, these data points will be removed from the measurements. After this, the resonance frequency and quality factor increase and decrease respectively, and then decay to their initial empty cavity values. The rise time of these signals is approximately $1 \mu \mathrm{s}$, which corresponds to the temporal resolution of the cavity. As can be seen in figures 4(b) and (d), both the resonance frequency and quality factor return to their empty cavity values within the detection limit after several tens of $\mu$ s, well before the next voltage pulse at approximately $333 \mu$ s. Therefore, the resonance frequency and quality factor measured at $t<0$, so in the recorded time before the first voltage pulse, can be averaged and subsequently used as empty cavity values. Doing so has the advantage that a separate measurement of the empty cavity values is not required. This minimises potential drift of the resonance frequency that might occur between the empty cavity measurement and the discharge measurement due to, for example, temperature fluctuations in the laboratory. Typically, a complete measurement for one set of operating parameters takes several minutes. 
The microwave power used in the measurements presented in figure 4 , as well as in the results section, is $P_{\text {in }}=0.1 \mathrm{~mW}$. To test whether the microwave fields influence the results, for example by heating the electrons and prolonging the decay, these measurements were repeated using various input powers from $0.1 \mathrm{~mW}$ up to $40 \mathrm{~mW}$. No significant changes were found, which confirms that the microwave fields do not influence the results in this case.

\subsection{Microwave cavity resonance spectroscopy}

2.2.1. Cavity perturbation theory. To relate the measured relative shift in resonance frequency $\Delta f / f_{1}$ and the changes in quality factor $\Delta(1 / Q)$ to properties of the discharge, cavity perturbation theory is used [35-37]. The plasma itself will be approximated by a cylindrical volume $V_{\mathrm{p}}=\pi r_{\mathrm{p}}^{2} l_{\mathrm{p}}$ with uniform properties, which will be further specified shortly. By treating the change in complex permittivity of the medium, $\Delta \tilde{\varepsilon}=\tilde{\varepsilon}_{2}-\varepsilon_{0}$, caused by the presence of the plasma as a perturbation to the empty cavity, the following equation can be derived [37] (see appendix for more details):

$$
\frac{\Delta \omega}{\omega_{1}}+\mathrm{i} \frac{1}{2} \Delta\left(\frac{1}{Q}\right)=-\frac{\iiint_{V_{\text {cav }}} \Delta \tilde{\varepsilon}\left|\boldsymbol{E}_{1}\right|^{2} \mathrm{~d}^{3} \boldsymbol{r}}{2 \varepsilon_{0} \iiint_{V_{\text {cav }}}\left|\boldsymbol{E}_{1}\right|^{2} \mathrm{~d}^{3} \boldsymbol{r}},
$$

where $\boldsymbol{E}_{1}$ is the unperturbed microwave electric field, and $\varepsilon_{0}$ is the vacuum permittivity.

Usually, small perturbations would require that the plasma-electron frequency $\omega_{\mathrm{pe}}$ is smaller than the microwave frequency $\omega$, such that the plasma does not shield the microwave fields. The plasma-electron frequency is defined as

$$
\omega_{\mathrm{pe}}=\sqrt{\frac{n_{\mathrm{e}} e^{2}}{\varepsilon_{0} m_{\mathrm{e}}}},
$$

where $n_{\mathrm{e}}$ is the electron density, $e$ is the elementary charge, and $m_{\mathrm{e}}$ is the electron mass. For the $\mathrm{TM}_{010}$ mode at $3.51 \mathrm{GHz}$, this condition would only be met for electron densities lower than about $10^{17} \mathrm{~m}^{-3}$. However, when the typical plasma dimension is smaller than the (collisional) skin depth, this constraint is circumvented, and higher densities can be measured [38]. This is the case for our guided streamer discharges in $\mathrm{N}_{2}$ with a typical radius of $150 \mu \mathrm{m}$. The fact that the perturbations indeed remain small in the present case is demonstrated by the small relative changes in resonance frequency and quality factor in figure 4.

In order to use (4) to translate the measured relative frequency shift and reciprocal quality factor to properties of the plasma, two things are required: the plasma permittivity, and the electric field of the $\mathrm{TM}_{010}$ mode of the cavity.

2.2.2. Electric field distribution of the $T M_{010}$ mode. Since our cavity has two concentric holes on its symmetry axis, as well as a dielectric (the quartz tube) and a conductor (the needle electrode) in its vicinity, the field distribution will inevitably be different from the ideal case. Therefore, a model is used to

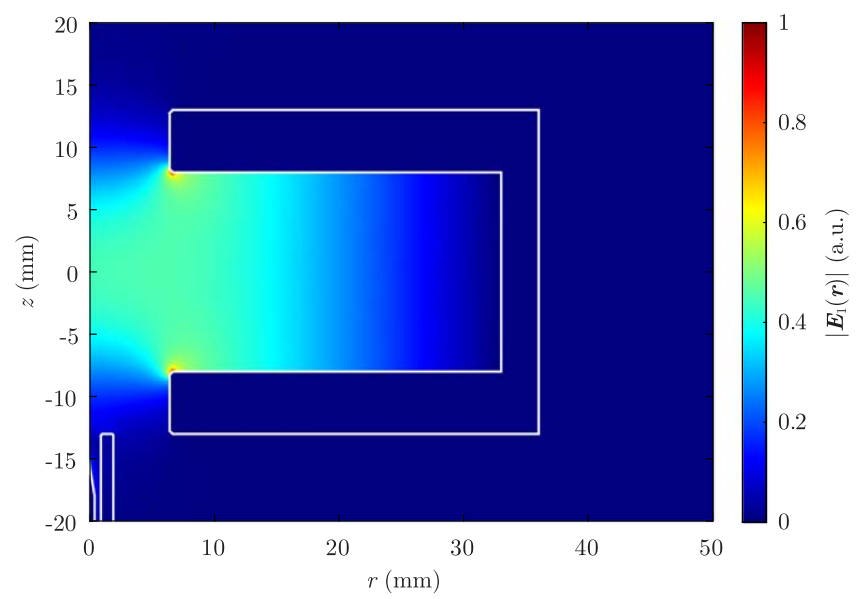

Figure 5. Electric field magnitude of the $\mathrm{TM}_{010}$ mode obtained from the model. Outlines of the cavity, the quartz tube and the needle are given by the white lines.

numerically determine the electric field distribution $\boldsymbol{E}_{1}(\boldsymbol{r})$ of the empty cavity. This is done using the frequency domain electromagnetic wave modelling tools in COMSOL. As the $\mathrm{TM}_{010}$ mode is cylindrically symmetric, a $2 \mathrm{D}$ axisymmetric model can be used. A resonance frequency of $3.51 \mathrm{GHz}$ is obtained from the model, confirming the experimentally measured value in the setup. The corresponding electric field magnitude distribution is shown in figure 5. It can be seen that the electric field 'leaks' through the two holes and that amplification occurs at the inner corners of the two holes.

2.2.3. Permittivity of a collisional plasma. The permittivity of a plasma subjected to a time-harmonic electric field at angular frequency $\omega$ is given by [39]

$$
\tilde{\varepsilon}_{2}=\varepsilon_{0}-\mathrm{i} \frac{\tilde{\sigma}}{\omega}
$$

where $\tilde{\sigma}$ is the complex plasma conductivity.

A general equation for the complex conductivity of a plasma can be obtained from kinetic theory [40]:

$$
\tilde{\sigma}=-\frac{2}{3} \varepsilon_{0} \omega_{\mathrm{pe}}^{2} \int_{0}^{\infty} \frac{\epsilon^{3 / 2}}{\nu_{\mathrm{m}}(\epsilon)+\mathrm{i} \omega} \frac{\mathrm{d} f}{\mathrm{~d} \epsilon} \mathrm{d} \epsilon,
$$

where $\epsilon$ is the electron energy, $\nu_{\mathrm{m}}(\epsilon)$ is the electron momentum transfer collision frequency, and $f(\epsilon)$ is the electron energy distribution function (EEDF) with normalisation $\int_{0}^{\infty} \sqrt{\epsilon} f(\epsilon) \mathrm{d} \epsilon=1$. However, for the current purpose, (7) can be expressed more conveniently as

$$
\tilde{\sigma}=\varepsilon_{0} \frac{\omega_{\mathrm{pe}}^{2}}{\nu_{\text {eff }}+\mathrm{i} \omega}=\varepsilon_{0} \frac{\omega_{\mathrm{pe}}^{2}}{\nu_{\text {eff }}^{2}+\omega^{2}}\left(\nu_{\mathrm{eff}}-\mathrm{i} \omega\right),
$$

where $\nu_{\text {eff }}$ is the effective collision frequency, defined as [41]

$$
\nu_{\mathrm{eff}}=\frac{\int_{0}^{\infty} \epsilon^{3 / 2} \frac{\nu_{\mathrm{m}}(\epsilon)}{\nu_{\mathrm{m}}^{2}(\epsilon)+\omega^{2}} \frac{\mathrm{d} f}{\mathrm{~d} \epsilon} \mathrm{d} \epsilon}{\int_{0}^{\infty} \epsilon^{3 / 2} \frac{1}{\nu_{\mathrm{m}}^{2}(\epsilon)+\omega^{2}} \frac{\mathrm{d} f}{\mathrm{~d} \epsilon} \mathrm{d} \epsilon} .
$$


Substituting (8) in (6) gives the plasma permittivity

$$
\tilde{\varepsilon}_{2}=\varepsilon_{0}\left[1-\frac{\omega_{\mathrm{pe}}^{2}}{\left(\nu_{\mathrm{eff}}^{2}+\omega^{2}\right)}-\mathrm{i} \frac{\nu_{\mathrm{eff}}}{\omega} \frac{\omega_{\mathrm{pe}}^{2}}{\left(\nu_{\mathrm{eff}}^{2}+\omega^{2}\right)}\right] \text {. }
$$

Using the plasma permittivity of (10) in (4), and separating the real and imaginary parts, leads to the following equations for the relative frequency shift and change in reciprocal quality factor [42]:

$$
\begin{gathered}
\frac{\Delta f}{f_{1}}=\frac{\Delta \omega}{\omega_{1}}=\frac{\iiint_{V_{\mathrm{cav}}} \frac{\omega_{\mathrm{pe}}^{2}}{\left(\omega_{1}^{2}+\nu_{\mathrm{eff}}^{2}\right)}\left|\boldsymbol{E}_{1}\right|^{2} \mathrm{~d}^{3} \boldsymbol{r}}{2 \iiint_{V_{\mathrm{cav}}}\left|\boldsymbol{E}_{1}\right|^{2} \mathrm{~d}^{3} \boldsymbol{r}}, \\
\Delta\left(\frac{1}{Q}\right)=\frac{\iiint_{V_{\mathrm{cav}}} \frac{\nu_{\mathrm{eff}}}{\omega_{1}} \frac{\omega_{\mathrm{pe}}^{2}}{\left(\omega_{1}^{2}+\nu_{\mathrm{eff}}^{2}\right)}\left|\boldsymbol{E}_{1}\right|^{2} \mathrm{~d}^{3} \boldsymbol{r}}{\iiint_{V_{\mathrm{cav}}}\left|\boldsymbol{E}_{1}\right|^{2} \mathrm{~d}^{3} \boldsymbol{r}} .
\end{gathered}
$$

2.2.4. Obtaining $n_{e}$ and $\nu_{\text {eff }}$ from $\Delta f / f_{1}$ and $\Delta(1 / Q)$. As mentioned, the plasma is approximated by a uniform cylindrical volume $V_{\mathrm{p}}=\pi r_{\mathrm{p}}^{2} l_{\mathrm{p}}$ with electron density $n_{\mathrm{e}}$ and effective collision frequency $\nu_{\text {eff }}$. Changes due to transport are neglected and the plasma volume is assumed constant in the analysis. In this case, (11) and (12) can be simplified to

$$
\begin{gathered}
\frac{\Delta f}{f_{1}}=\frac{1}{2} \frac{\omega_{\mathrm{pe}}^{2}}{\left(\omega_{1}^{2}+\nu_{\mathrm{eff}}^{2}\right)} \mathcal{V}, \\
\Delta\left(\frac{1}{Q}\right)=\frac{\nu_{\mathrm{eff}}}{\omega_{1}} \frac{\omega_{\mathrm{pe}}^{2}}{\left(\omega_{1}^{2}+\nu_{\mathrm{eff}}^{2}\right)} \mathcal{V},
\end{gathered}
$$

where $\mathcal{V}$ is the ratio of the effective (field-squared-weighted) plasma volume and the effective (field-squared-weighted) cavity volume given by

$$
\mathcal{V}=\frac{\iiint_{V_{\mathrm{p}}}\left|\boldsymbol{E}_{1}\right|^{2} \mathrm{~d}^{3} \boldsymbol{r}}{\iiint_{V_{\text {cav }}}\left|\boldsymbol{E}_{1}\right|^{2} \mathrm{~d}^{3} \boldsymbol{r}}
$$

which is calculated using the field distribution from the numerical model. The volume integral in the numerator of (15) is taken only over the space that the plasma occupies. Furthermore, it should be noted that volume integral over $V_{\text {cav }}$ in the denominator of (15) is not just the 'inner volume' enclosed by the cavity, but rather the entire space that the microwave fields permeate. For this reason, the volume integral over $V_{\text {cav }}$ is taken over the entire domain of the model.

From (13) and (14), first the effective collision frequency is determined as

$$
\begin{aligned}
\nu_{\mathrm{eff}} & =\omega_{1} \frac{1}{2} \frac{\Delta(1 / Q)}{\Delta f / f_{1}} \\
& =\pi f_{1} \frac{\Delta(1 / Q)}{\Delta f / f_{1}} .
\end{aligned}
$$

Interestingly, $\nu_{\text {eff }}$ does not depend on $\mathcal{V}$ and is therefore also independent of our estimation of $V_{\mathrm{p}}$. With the effective collision frequency known, the electron density can be determined using (13) as

$$
\begin{aligned}
n_{\mathrm{e}} & =2 \frac{\varepsilon_{0} m_{\mathrm{e}}}{e^{2}} \frac{\nu_{\mathrm{eff}}^{2}+\omega_{1}^{2}}{\mathcal{V}} \frac{\Delta f}{f_{1}} \\
& =2 \frac{\varepsilon_{0} m_{\mathrm{e}}}{e^{2}} \frac{\nu_{\mathrm{eff}}^{2}+4 \pi^{2} f_{1}^{2}}{\mathcal{V}} \frac{\Delta f}{f_{1}},
\end{aligned}
$$

where the definition of the plasma-electron frequency (5) was used. Equivalently, (14) could be used to determine the electron density, but the result would be the same. In contrast to the effective collision frequency, the electron density does depend on $\mathcal{V}$ and the estimated plasma volume $V_{\mathrm{p}}$. In the results section, a constant plasma radius $r_{\mathrm{p}}=150 \mu \mathrm{m}$ and length $l_{\mathrm{p}}=10 \mathrm{~mm}$ are used, resulting in $\mathcal{V}=7.9 \times 10^{-6}$. These dimensions are based on images of the optical emission recorded for discharges in the absence of the cavity [33]. However, errors in this estimation will directly translate to errors in the calculated electron density. The presence of the cavity, which effectively acts as a ground for the plasma source, could potentially alter the discharge. While the presence of the cavity decreases the lowest operation voltage at which discharges can be sustained from 6 to $4 \mathrm{kV}$, the appearance of the produced guided streamers remains similar. Nevertheless, to assess the influence of the cavity on the dimensions of the discharge more precisely, a cavity with optical access to the discharge is required, as will be further discussed in the outlook. Additionally, in reality convective and diffusive transport will change the electron density distribution in the time between discharges. To evaluate the sensitivity of the electron density to the estimated plasma volume, $\mathcal{V}$ is also calculated for $r_{\mathrm{p}}=100 \mu \mathrm{m}$ and $l_{\mathrm{p}}=7.5 \mathrm{~mm}$, and for $r_{\mathrm{p}}=200 \mu \mathrm{m}$ and $l_{\mathrm{p}}=12.5 \mathrm{~mm}$. This results in $\mathcal{V}=1.7 \times 10^{-6}$ and $\mathcal{V}=2.1 \times 10^{-5}$, respectively. This shows that the absolute values of the obtained electron densities will only be accurate up to their order of magnitude. Nevertheless, since the error introduced by the plasma volume is systematic, the temporal behaviour of the electron density is still captured by these measurements.

\subsection{Global model}

To compare results from the MCRS measurements to simulations, the discharges are modelled using a global model in PLASIMO $[43,44]$. In this model, the densities $n_{i}$ of species $i$ are calculated from

$$
\frac{\mathrm{d} n_{i}}{\mathrm{~d} t}=S_{i}
$$

where $S_{i}$ is the net rate at which the species are produced (or destroyed) in their respective reactions. Like in the analysis of the measurements, transport is neglected here. Since the discharges mostly take place in a stream of pure $\mathrm{N}_{2}$, a pure $\mathrm{N}_{2}$ chemistry is used. The model includes 11 species and 34 reactions, which are listed in table 1 . The rates of the electron impact reactions (R1-R6) are computed from the SIGLO database [45] using BOLSIG+ [46]. Additionally, the 
Table 1. Reactions included in the global model. Units of the electron temperature $T_{\mathrm{e}}$ and effective ion temperatures $T_{\mathrm{eff}, \mathrm{i}}$ are $\mathrm{K}$. The rates of the electron impact reactions (R1-R6) are computed from the SIGLO database [45] using BOLSIG+ [46].

\begin{tabular}{|c|c|c|c|}
\hline No. & Reaction & Rate coefficient & References \\
\hline R1 & $\mathrm{N}_{2}+\mathrm{e} \rightarrow \mathrm{N}_{2}+\mathrm{e}$ & BOLSIG+ & {$[45]$} \\
\hline R2 & $\mathrm{N}_{2}+\mathrm{e} \rightarrow \mathrm{N}_{2}(\mathrm{~A})+\mathrm{e}$ & BOLSIG+ & [45] \\
\hline R3 & $\mathrm{N}_{2}+\mathrm{e} \rightarrow \mathrm{N}_{2}(\mathrm{~B})+\mathrm{e}$ & BOLSIG+ & [45] \\
\hline R4 & $\mathrm{N}_{2}+\mathrm{e} \rightarrow \mathrm{N}_{2}\left(\mathrm{a}^{\prime}\right)+\mathrm{e}$ & BOLSIG+ & [45] \\
\hline R5 & $\mathrm{N}_{2}+\mathrm{e} \rightarrow \mathrm{N}_{2}(\mathrm{C})+\mathrm{e}$ & BOLSIG+ & [45] \\
\hline R6 & $\mathrm{N}_{2}+\mathrm{e} \rightarrow \mathrm{N}_{2}^{+}+\mathrm{e}+\mathrm{e}$ & BOLSIG+ & {$[45]$} \\
\hline R7 & $\mathrm{N}_{2}(\mathrm{~A})+\mathrm{N}_{2}\left(\mathrm{a}^{\prime}\right) \rightarrow \mathrm{N}_{4}^{+}+\mathrm{e}$ & $4 \times 10^{-18} \mathrm{~m}^{3} \mathrm{~s}^{-1}$ & [47] \\
\hline R8 & $\mathrm{N}_{2}\left(\mathrm{a}^{\prime}\right)+\mathrm{N}_{2}\left(\mathrm{a}^{\prime}\right) \rightarrow \mathrm{N}_{4}^{+}+\mathrm{e}$ & $1 \times 10^{-17} \mathrm{~m}^{3} \mathrm{~s}^{-1}$ & [47] \\
\hline R9 & $\mathrm{N}^{+}+\mathrm{e}+\mathrm{N}_{2} \rightarrow \mathrm{N}+\mathrm{N}_{2}$ & $6.0 \times 10^{-39}\left(300 / T_{\mathrm{e}}\right)^{1.5} \mathrm{~m}^{6} \mathrm{~s}^{-1}$ & [47] \\
\hline $\mathrm{R} 10$ & $\mathrm{~N}_{2}^{+}+\mathrm{e} \rightarrow \mathrm{N}+\mathrm{N}$ & $1.8 \times 10^{-13}\left(300 / T_{\mathrm{e}}\right)^{0.39} \mathrm{~m}^{3} \mathrm{~s}^{-1}$ & [47] \\
\hline R11 & $\mathrm{N}_{3}^{+}+\mathrm{e} \rightarrow \mathrm{N}+\mathrm{N}_{2}$ & $2 \times 10^{-13}\left(300 / T_{\mathrm{e}}\right)^{0.5} \mathrm{~m}^{3} \mathrm{~s}^{-1}$ & [47] \\
\hline R12 & $\mathrm{N}_{4}^{+}+\mathrm{e} \rightarrow \mathrm{N}_{2}+\mathrm{N}_{2}$ & $2.3 \times 10^{-12}\left(300 / T_{\mathrm{e}}\right)^{0.53} \mathrm{~m}^{3} \mathrm{~s}^{-1}$ & [47] \\
\hline R13 & $\mathrm{N}^{+}+\mathrm{N}+\mathrm{N}_{2} \rightarrow \mathrm{N}_{2}^{+}+\mathrm{N}_{2}$ & $1 \times 10^{-41} \mathrm{~m}^{6} \mathrm{~s}^{-1}$ & [47] \\
\hline R14 & $\mathrm{N}^{+}+\mathrm{N}_{2}+\mathrm{N}_{2} \rightarrow \mathrm{N}_{3}^{+}+\mathrm{N}_{2}$ & $1.7 \times 10^{-41}\left(300 / T_{\mathrm{eff}, \mathrm{N}^{+}}\right)^{2.1} \mathrm{~m}^{6} \mathrm{~s}^{-1}$ & [47] \\
\hline R15 & $\mathrm{N}_{2}^{+}+\mathrm{N} \rightarrow \mathrm{N}^{+}+\mathrm{N}_{2}$ & $7.2 \times 10^{-19}\left(T_{\mathrm{eff}, \mathrm{N}_{2}^{+}} / 300\right) \mathrm{m}^{3} \mathrm{~s}^{-1}$ & [47] \\
\hline R16 & $\mathrm{N}_{2}^{+}+\mathrm{N}_{2}+\mathrm{N} \rightarrow \mathrm{N}_{3}^{+}+\mathrm{N}$ & $9 \times 10^{-42} \exp \left(400 / T_{\mathrm{eff}, \mathrm{N}_{2}^{+}}\right) \mathrm{m}^{6} \mathrm{~s}^{-1}$ & [47] \\
\hline R17 & $\mathrm{N}_{2}^{+}+\mathrm{N}_{2}+\mathrm{N}_{2} \rightarrow \mathrm{N}_{4}^{+}+\mathrm{N}_{2}$ & $5.2 \times 10^{-41}\left(300 / T_{\mathrm{eff}, \mathrm{N}_{2}^{+}}\right)^{2.2} \mathrm{~m}^{6} \mathrm{~s}^{-1}$ & [47] \\
\hline R18 & $\mathrm{N}_{3}^{+}+\mathrm{N} \rightarrow \mathrm{N}_{2}^{+}+\mathrm{N}_{2}$ & $6.6 \times 10^{-17} \mathrm{~m}^{3} \mathrm{~s}^{-1}$ & [47] \\
\hline R19 & $\mathrm{N}_{4}^{+}+\mathrm{N} \rightarrow \mathrm{N}^{+}+\mathrm{N}_{2}+\mathrm{N}_{2}$ & $1 \times 10^{-17} \mathrm{~m}^{3} \mathrm{~s}^{-1}$ & [47] \\
\hline $\mathrm{R} 20$ & $\mathrm{~N}_{4}^{+}+\mathrm{N}_{2} \rightarrow \mathrm{N}_{2}^{+}+\mathrm{N}_{2}+\mathrm{N}_{2}$ & $2.1 \times 10^{-22} \exp \left(T_{\mathrm{eff}, \mathrm{N}_{4}^{+}} / 121\right) \mathrm{m}^{6} \mathrm{~s}^{-1}$ & [47] \\
\hline R21 & $\mathrm{N}_{2}(\mathrm{~A}) \rightarrow \mathrm{N}_{2}+h \nu$ & $5.0 \times 10^{-1} \mathrm{~s}^{-1}$ & [47] \\
\hline R22 & $\mathrm{N}_{2}(\mathrm{~B}) \rightarrow \mathrm{N}_{2}(\mathrm{~A})+h \nu$ & $1.34 \times 10^{5} \mathrm{~s}^{-1}$ & [47] \\
\hline R23 & $\mathrm{N}_{2}\left(\mathrm{a}^{\prime}\right) \rightarrow \mathrm{N}_{2}+h \nu$ & $1 \times 10^{2} \mathrm{~s}^{-1}$ & {$[47]$} \\
\hline R24 & $\mathrm{N}_{2}(\mathrm{C}) \rightarrow \mathrm{N}_{2}(\mathrm{~B})+h \nu$ & $2.45 \times 10^{7} \mathrm{~s}^{-1}$ & [47] \\
\hline $\mathrm{R} 25$ & $\mathrm{~N}_{2}(\mathrm{~A})+\mathrm{N} \rightarrow \mathrm{N}_{2}+\mathrm{N}$ & $2 \times 10^{-18} \mathrm{~m}^{3} \mathrm{~s}^{-1}$ & [47] \\
\hline $\mathrm{R} 26$ & $\mathrm{~N}_{2}(\mathrm{~A})+\mathrm{N}_{2} \rightarrow \mathrm{N}_{2}+\mathrm{N}_{2}$ & $3 \times 10^{-22} \mathrm{~m}^{3} \mathrm{~s}^{-1}$ & [47] \\
\hline R27 & $\mathrm{N}_{2}(\mathrm{~A})+\mathrm{N}_{2}(\mathrm{~A}) \rightarrow \mathrm{N}_{2}(\mathrm{~B})+\mathrm{N}_{2}$ & $3 \times 10^{-16} \mathrm{~m}^{3} \mathrm{~s}^{-1}$ & [47] \\
\hline $\mathrm{R} 28$ & $\mathrm{~N}_{2}(\mathrm{~A})+\mathrm{N}_{2}(\mathrm{~A}) \rightarrow \mathrm{N}_{2}(\mathrm{C})+\mathrm{N}_{2}$ & $1.5 \times 10^{-16} \mathrm{~m}^{3} \mathrm{~s}^{-1}$ & {$[47]$} \\
\hline R29 & $\mathrm{N}_{2}(\mathrm{~B})+\mathrm{N}_{2} \rightarrow \mathrm{N}_{2}+\mathrm{N}_{2}$ & $2 \times 10^{-18} \mathrm{~m}^{3} \mathrm{~s}^{-1}$ & [47] \\
\hline R30 & $\mathrm{N}_{2}(\mathrm{~B})+\mathrm{N}_{2} \rightarrow \mathrm{N}_{2}(\mathrm{~A})+\mathrm{N}_{2}$ & $3 \times 10^{-17} \mathrm{~m}^{3} \mathrm{~s}^{-1}$ & [47] \\
\hline R31 & $\mathrm{N}_{2}\left(\mathrm{a}^{\prime}\right)+\mathrm{N}_{2} \rightarrow \mathrm{N}_{2}(\mathrm{~B})+\mathrm{N}_{2}$ & $1.9 \times 10^{-19} \mathrm{~m}^{3} \mathrm{~s}^{-1}$ & [47] \\
\hline R32 & $\mathrm{N}_{2}(\mathrm{C})+\mathrm{N}_{2} \rightarrow \mathrm{N}_{2}\left(\mathrm{a}^{\prime}\right)+\mathrm{N}_{2}$ & $1 \times 10^{-17} \mathrm{~m}^{3} \mathrm{~s}^{-1}$ & {$[47]$} \\
\hline R33 & $\mathrm{N}+\mathrm{N}+\mathrm{N}_{2} \rightarrow \mathrm{N}_{2}(\mathrm{~A})+\mathrm{N}_{2}$ & $1.7 \times 10^{-45} \mathrm{~m}^{6} \mathrm{~s}^{-1}$ & [47] \\
\hline R34 & $\mathrm{N}+\mathrm{N}+\mathrm{N}_{2} \rightarrow \mathrm{N}_{2}(\mathrm{~B})+\mathrm{N}_{2}$ & $2.4 \times 10^{-45} \mathrm{~m}^{6} \mathrm{~s}^{-1}$ & [47] \\
\hline
\end{tabular}

electron energy density is calculated from

$$
\frac{\mathrm{d}}{\mathrm{d} t}\left(\frac{3}{2} n_{\mathrm{e}} k_{\mathrm{B}} T_{\mathrm{e}}\right)=P_{\text {in }}+P_{\text {elastic }}+P_{\text {inelastic }}
$$

where $k_{\mathrm{B}}$ is the Boltzmann constant, $T_{\mathrm{e}}$ is the electron temperature (i.e. the temperature associated with the average electron energy), $P_{\text {in }}$ in the input power density, and $P_{\text {elastic }}$ and $P_{\text {inelastic }}$ are the contributions to the electron energy density from elastic and inelastic collisions respectively. To avoid effects of the initial values for the species, the model is run until a periodic steady state is obtained.

The input power density of the experiment is not exactly known for our plasma source. For this reason, a power density resembling the applied voltage pulses is used, i.e. $500 \mathrm{~ns}$ wide pulses with linearly rising and falling edges of $40 \mathrm{~ns}$. The peak power density of the pulses is varied between $P_{\text {in }}=10^{9}$ $\mathrm{W} \mathrm{m}{ }^{-3}$ and $P_{\text {in }}=10^{11} \mathrm{~W} \mathrm{~m}^{-3}$ to investigate the effects on the resulting electron density and temperature. These values correspond to an energy dissipation per discharge between approximately 1 and $100 \mu \mathrm{J}$ for an estimated plasma volume of $V_{\mathrm{p}} \approx 10^{-9} \mathrm{~m}^{3}$. In figure $6, n_{\mathrm{e}}$ and $T_{\mathrm{e}}$ are shown for each of the input power densities for an entire period at a repetition rate of $3 \mathrm{kHz}$.

For each of the tested input power densities, the electron temperature rapidly increases to about $3 \mathrm{eV}$ at the start of the pulse. After the pulse it decays to less than $0.1 \mathrm{eV}$ in several $100 \mathrm{~ns}$ for $P_{\text {in }}=10^{9} \mathrm{~W} \mathrm{~m}^{-3}$ and in about $3 \mu \mathrm{s}$ for $P_{\text {in }}=10^{11}$ $\mathrm{W} \mathrm{m}^{-3}$. The peak electron density increases considerably for higher input power densities. Nevertheless, at larger time scales after the discharge, it is only weakly dependent on the input power density and the peak electron density. For these three input power densities, the electron densities differ by more than an order of magnitude only in the first several $\mu \mathrm{s}$ following the pulse and are within a factor of two from each other from about $10 \mu \mathrm{s}$ after the pulse. Nevertheless, the temporal resolution of the measurement is limited to about $1 \mu \mathrm{s}$, and these differences cannot be resolved in the measurements. Therefore detailed knowledge on the exact input 

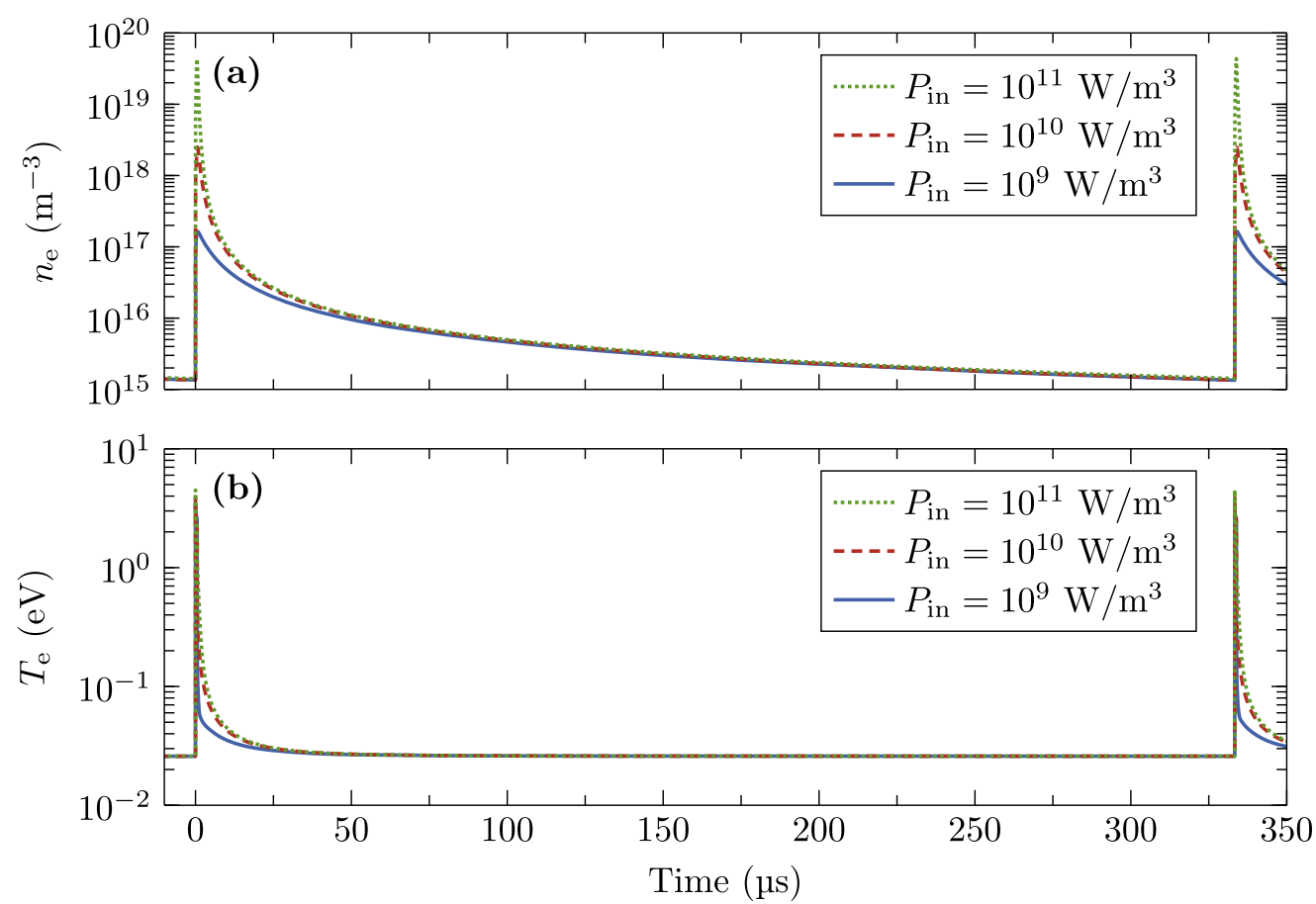

Figure 6. Temporal evolution in the global model of (a) the electron density and (b) the electron temperature between successive discharges at $3 \mathrm{kHz}$ for different input power densities.
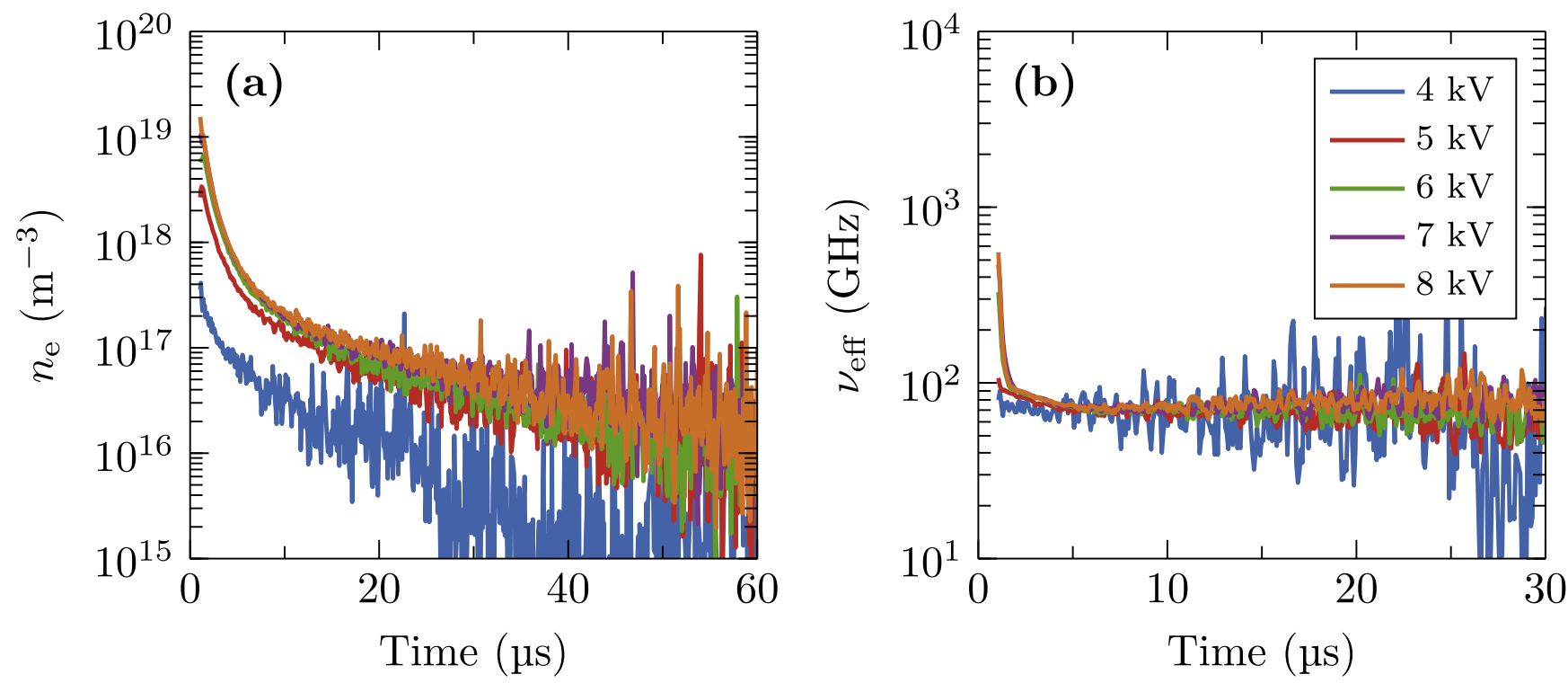

Figure 7. Measured (a) electron density, and (b) effective collision frequency, for different applied voltages at the fixed repetition frequency of $3 \mathrm{kHz}$.

power density is also not essential in comparing electron densities obtained from the measurements and the model in this case.

\section{Results and discussion}

Electron densities and effective collision frequencies are measured for various applied voltage and repetition frequencies. Figure 7 shows the results for different voltages at a fixed repetition frequency of $3 \mathrm{kHz}$, and figure 8 shows the results for different repetition frequencies at a fixed voltage of $6 \mathrm{kV}$. As mentioned before, when the HV pulse switches on and off there is interference in the measurement signal. The affected parts of the signals were removed from the graphs.

For each of the applied voltages in figure 7(a), a similar decay rate of the electron density can be observed. However, the absolute values increase for higher voltages. The maximum value that is measured, at about $1 \mu \mathrm{s}$ after the discharge, increases from about $4 \times 10^{17} \mathrm{~m}^{-3}$ for $4 \mathrm{kV}$ to $1 \times 10^{19} \mathrm{~m}^{-3}$ for $8 \mathrm{kV}$. These values are in the same range as those found in the global model, as shown in figure 6(a). 

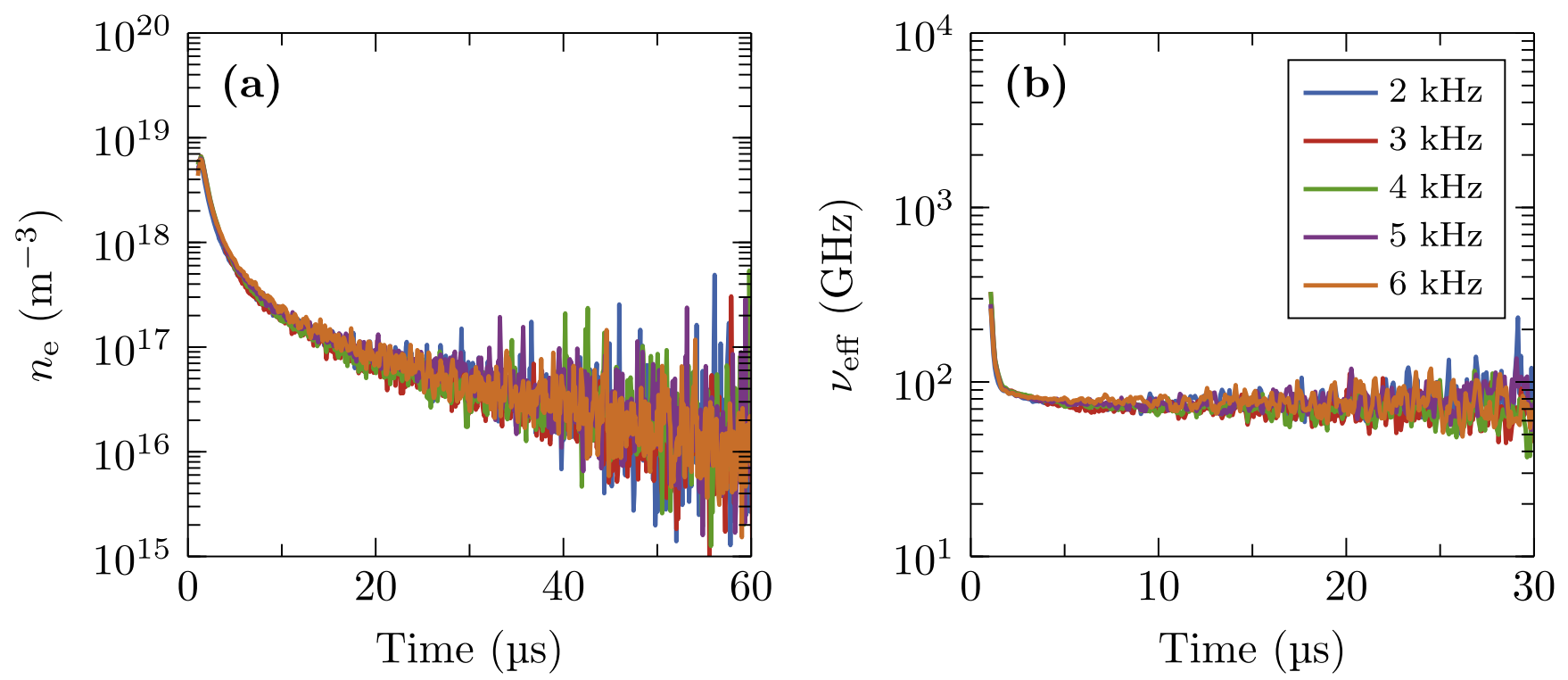

Figure 8. Measured (a) electron density and (b) effective collision frequency for different repetition frequencies at the fixed applied voltage of $6 \mathrm{kV}$.

Briefly after the discharge, the difference in electron density for the different applied voltages could be the result of the input power density, as shown by the model. Nevertheless, the global model also shows that the decay curves should converge to each other, within a factor of two after approximately $10 \mu \mathrm{s}$. Despite its lower signal-to-noise ratio, it can be seen that the curve measured for $4 \mathrm{kV}$ remains significantly below the others. This strongly indicates that the low electron densities found for $4 \mathrm{kV}$ are for a large part the result of an overestimation of the plasma volume, and hence $\mathcal{V}$, for this voltage. Looking at the electric field distribution in figure 5, it can be seen that shorter guided streamers will also not reach the regions where the electric field in the cavity is high. As the calculations for $\mathcal{V}$ in the previous section already indicated, this could easily result in an order of magnitude error in absolute values. These two things likely explain the large (apparent) increase in electron density from 4 to $5 \mathrm{kV}$.

The temporal evolution of the effective collision frequency is shown in figure 7(b) for each of the voltages. In each case, the effective collision frequency decays to a constant value of about $80 \mathrm{GHz}$. This value corresponds to the room temperature value $\nu_{\text {eff }}(300 \mathrm{~K})=76 \mathrm{GHz}$, which can be calculated from (9) using collision cross section data [48] and assuming a Maxwell-Boltzmann EEDF. The decay of the effective collision frequency occurs on a time scale of several $\mu \mathrm{s}$, which is significantly shorter than the time scale of the electron density decay. The decay of the effective collision frequency is related to the decrease in electron temperature, although a direct comparison between the two would require knowledge on the EEDF. Nevertheless, the global model also predicts that the electron temperature decays much faster than the electron density. A similar result to this was reported for a pulsed plasma jet in $\mathrm{He}$ [20].

In figure 7(b), it can be seen that the electron density and effective collision frequency do not depend on the repetition frequency. Although, there could still be differences in peak

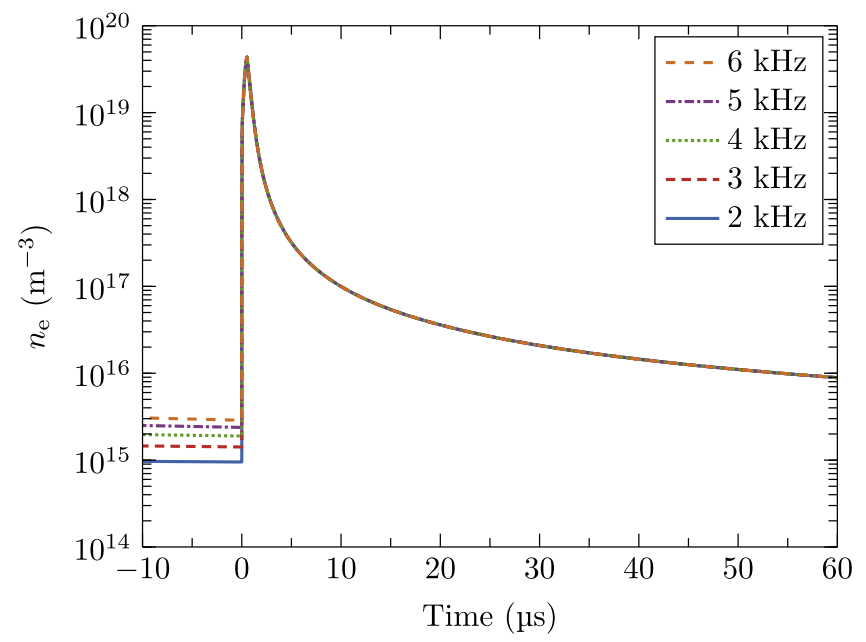

Figure 9. Electron densities for different repetition frequencies obtained from the global model. A pulsed input power density of $P_{\text {in }}=10^{11} \mathrm{~W} \mathrm{~m}^{-3}$ is used.

values that occur on a time scale shorter than $1 \mu \mathrm{s}$. To test this, the global model is run again, but this time for different repetition frequencies. The results are shown in figure 9, where it can be seen that the behaviour of the electron density is indeed similar at different repetition frequencies. Nevertheless, $2 \mathrm{kHz}$ is the lowest repetition frequency at which guided streamers can be maintained, and hence the lowest frequency where there is a memory effect that is responsible for reproducible discharges. For lower frequencies, the electron density becomes too low in the time between successive discharges. So, the electron density right before the discharges at $2 \mathrm{kHz}$ constitutes the minimum required seed electron density for guided streamers in $\mathrm{N}_{2}$. From figure 9 it can be seen that this is about $10^{15} \mathrm{~m}^{-3}$. The same order of magnitude for the minimum required seed electron density is reported for a pulsed plasma jet in pure $\mathrm{He}[12,49]$. 


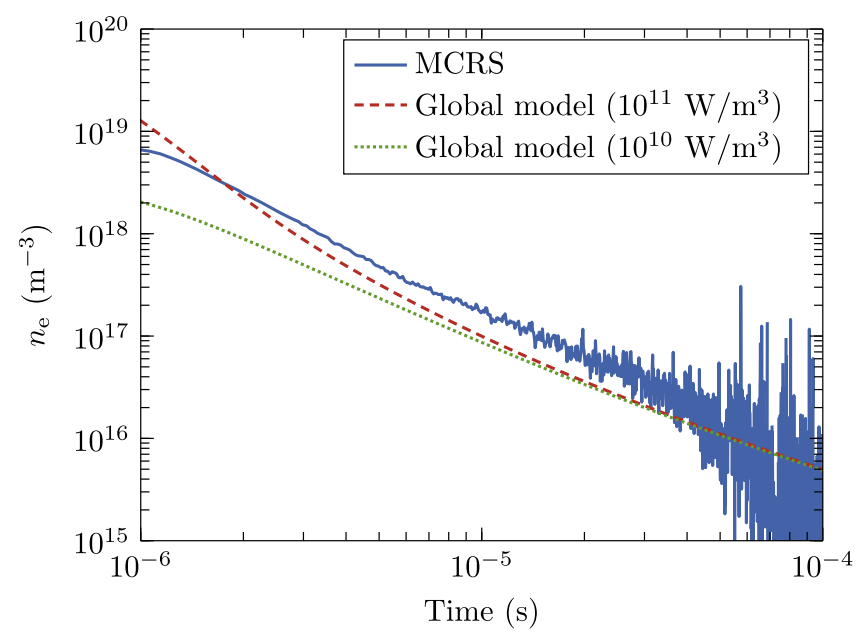

Figure 10. Comparison between electron density from the MCRS experiment at $6 \mathrm{kV}$ and $3 \mathrm{kHz}$, and the global model with input power densities of $10^{10}$ and $10^{11} \mathrm{~W} \mathrm{~m}^{-3}$.

Finally, to directly compare the decay rate of the electron density between the measurements and the model, the measured electron densities for an applied voltage of $6 \mathrm{kV}$ and repetition frequency of $3 \mathrm{kHz}$ are shown together with two electron density curves from the model corresponding to the two highest input power densities in figure 10. In fact, the measurements and the model show a good qualitative agreement. After about $10 \mu \mathrm{s}$, when the effects of the initial peak electron density are gone, the three curves are approximately parallel, indicating the same decay rate. It should be noted however that in both the analysis of measurements and in the global model transport of electrons is neglected. As a result, the decay might be somewhat faster in reality. Additionally, the model does not account for potential effects from the surrounding ambient air, such as the diffusion of $\mathrm{O}_{2}$ into the gas flow and the consequent attachment of electrons. However, from numerical flow simulations (without the presence of the cavity), most of the electrons are expected in a region where the $\mathrm{O}_{2}$ fraction is less than $1 \%$ [50]. Previous work by Nijdam et al on streamer discharges in $\mathrm{N}_{2} / \mathrm{O}_{2}$ mixtures has shown that there is a dependence of the electron density on the oxygen fraction between $0 \%$ and $1 \%$, but the differences are less than an order of magnitude [51]. This suggests that the error in our model due to neglecting the effects of $\mathrm{O}_{2}$ from the surrounding air can be expected to be less than an order of magnitude.

\section{Conclusions and outlook}

In this work, MCRS is applied to guided streamers generated in a pulsed plasma jet in $\mathrm{N}_{2}$. It is shown that electron densities, as well as the effective collision frequencies, can be measured using this technique from about $1 \mu \mathrm{s}$ up to approximately $60 \mu \mathrm{s}$ after the discharge, where the former time scale is limited by the response time of the cavity and the latter by the detection limit of about $10^{16} \mathrm{~m}^{-3}$. However, the assumptions on the spatial distribution of the electron density, which are required in the analysis of the measurements, limit the absolute accuracy of the electron density to about an order of magnitude. Despite the large uncertainty in the absolute values, the measured electron densities are in the same range as those predicted by a global model. There is also a good qualitative agreement in the decay rate between the measurements and the model. Furthermore, from the model it is evaluated that the minimum seed electron density required for reproducible guided streamers in $\mathrm{N}_{2}$ is of the order of $10^{15}$ $\mathrm{m}^{-3}$, which is similar to what is reported for pulsed plasma jets in He [12]. In addition to the electron density, the MCRS analysis provides information on the effective collision frequency of the electrons. It is found that the effective collision frequency drops to its room temperature value several $\mu$ s after the discharge, which corresponds to the rapid decrease in electron temperature that is observed in the model.

These results demonstrate that MCRS provides a useful electron density diagnostic for pulsed plasma jets in $\mathrm{N}_{2}$. In principle this method can also be applied to pulsed plasma jets in different feed gases, such as He or Ar, as well as to discharges or effluents of other common types of APPJs, such as radio-frequency driven plasma jets. In every case it should be confirmed that the changes in relative shift in resonance frequency and quality factor remain small, and that the microwave fields do not influence the results. For the present case of a pulsed plasma jet in $\mathrm{N}_{2}$, the following improvements have to be made to obtain more accurate quantitative electron densities. Firstly, the detection limit of around $10^{16} \mathrm{~m}^{-3}$ is still an order of magnitude too high to completely measure the evolution of the electron density between consecutive discharges. Potentially, using a higher quality factor cavity, and hence narrower resonance peaks, could improve the detection limit. However, this would be at the cost of temporal resolution. Another option is to increase the number of samples that are averaged. This would increase the measurement time, and it might be necessary to monitor and account for fluctuations in the lab environments in this case. Secondly, and more importantly, the accuracy in absolute electron densities has to be increased. Currently, the major source of uncertainty in the measurements originates from the estimation of the plasma volume. It would be useful to use a cavity with optical access to observe the discharge. This could, for example, be achieved by making a slit in the curved part of the cavity wall or by replacing it with a metal mesh. This way the emission of the discharge can be observed from a side-view using an ICCD camera and the effects of the presence of the cavity on the discharge can be assessed. This would help in estimating the initial plasma volume during the discharge. Furthermore, the plasma volume was assumed to be constant in this work. However, transport during the time between discharges will change the electron density distribution. To obtain accurate electron density values, especially at larger time scales, this should also be accounted for both in the analysis of the measurements and in the model. One way to do this would be to develop a spatial model of the complete system, including the microwave cavity and the pulsed discharges. Alternatively, the recently introduced multi-mode MCRS method could be used [32]. With this technique, the spatial electron 
density distribution can actually be reconstructed from measurements of multiple cavity modes. Therefore, applying multi-mode MCRS would avoid the need for assumptions of the electron density distribution.

\section{Appendix. Derivation of the perturbation equation}

First, the unperturbed cavity is considered. The electromagnetic fields in the cavity are described by Maxwell's equations. For time-harmonic fields, these are given by:

$$
\begin{gathered}
-\nabla \times \boldsymbol{E}_{1}=\mathrm{i} \tilde{\omega}_{1} \mu_{1} \boldsymbol{H}_{1}, \\
\nabla \times \boldsymbol{H}_{1}=\mathrm{i} \tilde{\omega}_{1} \varepsilon_{1} \boldsymbol{E}_{1},
\end{gathered}
$$

where $\tilde{\omega}_{1}$ is the unperturbed (complex) resonance frequency, $\varepsilon_{1}$ is the permittivity and $\mu_{1}$ is the permeability of the medium inside the cavity, and $\boldsymbol{E}_{1}$ and $\boldsymbol{H}_{1}$ are the unperturbed electric and magnetic microwave fields respectively. For the empty cavity, $\varepsilon_{1}=\varepsilon_{0}$ and $\mu_{1}=\mu_{0}$, where are $\varepsilon_{0}$ and $\mu_{0}$ are the vacuum permittivity and permeability respectively. In the case of an ideal lossless cavity, $\tilde{\omega}_{1}$ is purely real. In reality, however, it is a complex quantity given by $\tilde{\omega}_{1}=$ $\omega_{1}+\mathrm{i} \omega_{1} / 2 Q_{1}$.

Now a perturbation, in the form of a plasma, is introduced in the medium of the cavity. In the perturbed situation, Maxwell's equations become

$$
\begin{gathered}
-\nabla \times \boldsymbol{E}_{2}=\mathrm{i} \tilde{\omega}_{2} \tilde{\mu}_{2} \boldsymbol{H}_{2}, \\
\nabla \times \boldsymbol{H}_{2}=\mathrm{i} \tilde{\omega}_{2} \tilde{\varepsilon}_{2} \boldsymbol{E}_{2},
\end{gathered}
$$

where $\tilde{\omega}_{2}=\omega_{2}+\mathrm{i} \omega_{2} / 2 Q_{2}$ is the new complex resonance frequency, and $\tilde{\varepsilon}_{2}$ and $\tilde{\mu}_{2}$ are the permittivity and permeability of the plasma. The plasma permittivity and permeability are in general complex and can also be space dependent.

Multiplying (A.1) by $\boldsymbol{H}_{2}$ and (A.4) by $\boldsymbol{E}_{1}$ results in

$$
\begin{gathered}
\left(-\nabla \times \boldsymbol{E}_{1}\right) \cdot \boldsymbol{H}_{2}=\mathrm{i} \tilde{\omega}_{1} \mu_{0} \boldsymbol{H}_{1} \cdot \boldsymbol{H}_{2}, \\
\left(\nabla \times \boldsymbol{H}_{2}\right) \cdot \boldsymbol{E}_{1}=\mathrm{i} \tilde{\omega}_{2} \tilde{\varepsilon}_{2} \boldsymbol{E}_{2} \cdot \boldsymbol{E}_{1} .
\end{gathered}
$$

Adding (A.5) and (A.6), and using the identity

$$
\nabla \cdot(\boldsymbol{A} \times \boldsymbol{B})=\boldsymbol{B} \cdot(\nabla \times \boldsymbol{A})-\boldsymbol{A} \cdot(\nabla \times \boldsymbol{B}),
$$

this can be written as

$$
\nabla \cdot\left(\boldsymbol{H}_{2} \times \boldsymbol{E}_{1}\right)=\mathrm{i} \tilde{\omega}_{2} \tilde{\varepsilon}_{2} \boldsymbol{E}_{1} \cdot \boldsymbol{E}_{2}+\mathrm{i} \tilde{\omega}_{1} \mu_{0} \boldsymbol{H}_{1} \cdot \boldsymbol{H}_{2} .
$$

Similar operations can be applied to (A.2) and (A.3) to obtain

$$
\nabla \cdot\left(\boldsymbol{H}_{1} \times \boldsymbol{E}_{2}\right)=\mathrm{i} \tilde{\omega}_{2} \tilde{\mu}_{2} \boldsymbol{H}_{1} \cdot \boldsymbol{H}_{2}+\mathrm{i} \tilde{\omega}_{1} \varepsilon_{0} \boldsymbol{E}_{1} \cdot \boldsymbol{E}_{2} .
$$

The difference of (A.7) and (A.8) is

$$
\begin{aligned}
\nabla & \cdot\left(\boldsymbol{H}_{2} \times \boldsymbol{E}_{1}-\boldsymbol{H}_{1} \times \boldsymbol{E}_{2}\right) \\
& =\mathrm{i}\left(\tilde{\omega}_{2} \Delta \tilde{\varepsilon}+\varepsilon_{0} \Delta \tilde{\omega}\right) \boldsymbol{E}_{1} \cdot \boldsymbol{E}_{2}-\mathrm{i}\left(\tilde{\omega}_{2} \Delta \tilde{\mu}+\mu_{0} \Delta \tilde{\omega}\right) \boldsymbol{H}_{1} \cdot \boldsymbol{H}_{2},
\end{aligned}
$$

where $\Delta \tilde{\omega}=\tilde{\omega}_{2}-\tilde{\omega}_{1}, \Delta \tilde{\varepsilon}=\tilde{\varepsilon}_{2}-\varepsilon_{0}$ and $\Delta \tilde{\mu}=\tilde{\mu}_{2}-\mu_{0}$. Next, the left-hand side of (A.9) is integrated over the cavity volume $V_{\text {cav }}$, and the divergence theorem is used to show that this integral is equal to zero, as both $\boldsymbol{n} \times \boldsymbol{E}=0$ and $\boldsymbol{n} \times \boldsymbol{H}=0$ on the cavity surface $S_{\text {cav }}$ :

$$
\begin{aligned}
\iiint_{V_{\mathrm{cav}}} \nabla \cdot\left(\boldsymbol{H}_{2} \times \boldsymbol{E}_{1}-\boldsymbol{H}_{1} \times \boldsymbol{E}_{2}\right) \mathrm{d}^{3} \boldsymbol{r} \\
\quad=\oiint_{S_{\mathrm{cav}}}\left(\boldsymbol{H}_{2} \times \boldsymbol{E}_{1}-\boldsymbol{H}_{1} \times \boldsymbol{E}_{2}\right) \cdot \boldsymbol{n} \mathrm{d}^{2} \boldsymbol{r}=0 .
\end{aligned}
$$

Equivalently, integrating the right-hand side of (A.9) over the cavity volume yields

$$
\begin{aligned}
& \iiint_{V_{\text {cav }}}\left[\left(\tilde{\omega}_{2} \Delta \tilde{\varepsilon}+\varepsilon_{0} \Delta \tilde{\omega}\right) \boldsymbol{E}_{1} \cdot \boldsymbol{E}_{2}-\left(\tilde{\omega}_{2} \Delta \tilde{\mu}\right.\right. \\
& \left.\left.\quad+\mu_{0} \Delta \tilde{\omega}\right) \boldsymbol{H}_{1} \cdot \boldsymbol{H}_{2}\right] \mathrm{d}^{3} \boldsymbol{r}=0 .
\end{aligned}
$$

Finally, with some manipulation, this can be written as

$$
\frac{\Delta \tilde{\omega}}{\tilde{\omega}_{2}}=-\frac{\iiint_{V_{\text {cav }}}\left(\Delta \tilde{\varepsilon} \boldsymbol{E}_{1} \cdot \boldsymbol{E}_{2}-\Delta \tilde{\mu} \boldsymbol{H}_{1} \cdot \boldsymbol{H}_{2}\right) \mathrm{d}^{3} \boldsymbol{r}}{\iiint_{V_{\text {cav }}}\left(\varepsilon_{0} \boldsymbol{E}_{1} \cdot \boldsymbol{E}_{2}-\mu_{0} \boldsymbol{H}_{1} \cdot \boldsymbol{H}_{2}\right) \mathrm{d}^{3} \boldsymbol{r}} .
$$

Now some approximations will be made, where it is assumed that the perturbations by the plasma are small. Firstly, using $\omega_{2} \approx \omega_{1}$ and $Q_{1}, Q_{2} \gg 1$, the left-hand side of (A.12) can be approximated as

$$
\frac{\Delta \tilde{\omega}}{\tilde{\omega}_{2}} \approx \frac{\Delta \omega}{\omega_{1}}+\mathrm{i} \frac{1}{2} \Delta\left(\frac{1}{Q}\right) .
$$

Secondly, the perturbed microwave fields are approximated by the unperturbed fields, $\boldsymbol{E}_{2} \approx \boldsymbol{E}_{1}=\left|\boldsymbol{E}_{1}\right|$ and $\boldsymbol{H}_{2} \approx \boldsymbol{H}_{1}=\mathrm{i}\left|\boldsymbol{H}_{1}\right|$. Furthermore, the discharges discussed in this work are assumed to be unmagnetised, $\Delta \tilde{\mu}=0$, resulting in

$$
\begin{aligned}
\frac{\Delta \omega}{\omega_{1}}+\mathrm{i} \frac{1}{2} \Delta\left(\frac{1}{Q}\right) & =-\frac{\iiint_{V_{\text {cav }}} \Delta \tilde{\varepsilon}\left|\boldsymbol{E}_{1}\right|^{2} \mathrm{~d}^{3} \boldsymbol{r}}{\iiint_{V_{\text {cav }}}\left(\varepsilon_{0}\left|\boldsymbol{E}_{1}\right|^{2}+\mu_{0}\left|\boldsymbol{H}_{1}\right|^{2}\right) \mathrm{d}^{3} \boldsymbol{r}} \\
& =-\frac{\iiint_{V_{\text {cav }}} \Delta \tilde{\varepsilon}\left|\boldsymbol{E}_{1}\right|^{2} \mathrm{~d}^{3} \boldsymbol{r}}{2 \varepsilon_{0} \iiint_{V_{\text {cav }}}\left|\boldsymbol{E}_{1}\right|^{2} \mathrm{~d}^{3} \boldsymbol{r}}
\end{aligned}
$$

where in the last step $\iiint \varepsilon|\boldsymbol{E}|^{2} \mathrm{~d}^{3} \boldsymbol{r}=\iiint \mu|\boldsymbol{H}|^{2} \mathrm{~d}^{3} \boldsymbol{r}$ for a cavity at resonance was used [37].

\section{ORCID iDs}

Marc van der Schans (10) https://orcid.org/0000-00032195-8472

Peter Koelman (ib https://orcid.org/0000-0002-9987-6875 Job Beckers (1) https://orcid.org/0000-0001-6116-7013 Sander Nijdam (i) https://orcid.org/0000-0002-1310-6942

\section{References}

[1] Lu X, Laroussi M and Puech V 2012 Plasma Sources Sci. Technol. 21034005

[2] Winter J, Brandenburg R and Weltmann K D 2015 Plasma Sources Sci. Technol. 24064001

[3] Brandenburg R 2017 Plasma Sources Sci. Technol. 26053001

[4] Foest R, Kindel E, Lange H, Ohl A, Stieber M and Weltmann K D 2007 Contrib. Plasma Phys. 47 119-28

[5] Bárdos L and Baránková H 2010 Thin Solid Films 518 6705-13 
[6] West A, van der Schans M, Xu C, Cooke M and Wagenaars E 2016 Plasma Sources Sci. Technol. 25 02LT01

[7] Kong M G, Kroesen G, Morfill G, Nosenko T, Shimizu T, van Dijk J and Zimmermann J L 2009 New J. Phys. 11 115012

[8] Keidar M, Yan D, Beilis I I, Trink B and Sherman J H 2018 Trends Biotechnol. 36 586-93

[9] Teschke M, Kedzierski J, Finantu-Dinu E, Korzec D and Engemann J 2005 IEEE Trans. Plasma Sci. 33 310-1

[10] Lu X and Laroussi M 2006 J. Appl. Phys. 100063302

[11] Lu X, Naidis G V, Laroussi M and Ostrikov K 2014 Phys. Rep. 540 123-66

[12] Lu X and Ostrikov K K 2018 Appl. Phys. Rev. 5031102

[13] Nikiforov A Y, Leys C, Gonzalez M A and Walsh J L 2015 Plasma Sources Sci. Technol. 24034001

[14] van Gessel A F H, Carbone E A D, Bruggeman P J and van der Mullen J J A M 2012 Plasma Sources Sci. Technol. 21015003

[15] van Gessel B, Brandenburg R and Bruggeman P 2013 Appl. Phys. Lett. 103064103

[16] Hübner S, Sousa J S, van der Mullen J and Graham W G 2015 Plasma Sources Sci. Technol. 24054005

[17] Hübner S, Hofmann S, van Veldhuizen E M and Bruggeman P J 2013 Plasma Sources Sci. Technol. 22 065011

[18] Hübner S, Sousa J S, Puech V, Kroesen G M W and Sadeghi N 2014 J. Phys. D. Appl. Phys. 47432001

[19] Klarenaar B L M, Guaitella O, Engeln R and Sobota A 2018 Plasma Sources Sci. Technol. 27085004

[20] Lu X P and Laroussi M 2008 Appl. Phys. Lett. 92051501

[21] Ito Y, Sakai O and Tachibana K 2010 Plasma Sources Sci. Technol. 19025006

[22] Wang X, Stockett P, Jagannath R, Bane S and Shashurin A 2018 Plasma Sources Sci. Technol. 27 07LT02

[23] Haverlag M, Kroesen G M W, Bisschops T H J and de Hoog F J 1991 Plasma Chem. Plasma Process. 11 357-70

[24] Stoffels E, Stoffels W W, Vender D, Kando M, Kroesen G M W and de Hoog F J 1995 Phys. Rev. E 51 2425-35

[25] Beckers J, Stoffels W W and Kroesen G M W 2009 J. Phys. D. Appl. Phys. 42155206

[26] Van De Wetering F M J H, Beckers J and Kroesen G M W 2012 J. Phys. D. Appl. Phys. 45485205

[27] van de Wetering F M J H, Brooimans R J C, Nijdam S, Beckers J and Kroesen G M W 2015 J. Phys. D. Appl. Phys. 48035204

[28] Franek J B, Nogami S H, Demidov V I, Koepke M E and Barnat E V 2015 Plasma Sources Sci. Technol. 24034009
[29] Beckers J, van der Horst R M, Osorio E A, Kroesen G M W and Banine V Y 2016 Plasma Sources Sci. Technol. 25035010

[30] van der Horst R M et al 2016 J. Phys. D. Appl. Phys. 49 145203

[31] van der Horst R M, Osorio E A, Banine V Y and Beckers J 2016 Plasma Sources Sci. Technol. 25015012

[32] Beckers J, van de Wetering F M J H, Platier B, van Ninhuijs M A W, Brussaard G J H, Banine V Y and Luiten O J 2019 J. Phys. D. Appl. Phys. 52034004

[33] van der Schans M, Böhm P, Teunissen J, Nijdam S, IJzerman W and Czarnetzki U 2017 Plasma Sources Sci. Technol. 26115006

[34] Jackson J D 1999 Classical Electrodynamics 3rd edn (New York: Wiley)

[35] Slater J C 1946 Rev. Mod. Phys. 18 441-512

[36] Biondi M A 1951 Rev. Sci. Instrum. 22 500-2

[37] Harrington R F 2001 Time-Harmonic Electromagnetic Fields (New York: Wiley-IEEE Press)

[38] Franek J B, Nogami S H, Demidov V I, Koepke M E and Barnat E V 2016 Plasma Sources Sci. Technol. 25 038002

[39] Lieberman M A and Lichtenberg A J 2005 Principles of Plasma Discharges and Materials Processing (New York: Wiley)

[40] Lister G G, Li Y and Godyak V A 1996 J. Appl. Phys. 79 8993-7

[41] McColl W, Brooks C and Brake M L 1993 J. Appl. Phys. 74 3724-35

[42] Buchsbaum S J and Brown S C 1957 Phys. Rev. 106 196-9

[43] van Dijk J, Peerenboom K, Jimenez M, Mihailova D and van der Mullen J 2009 J. Phys. D. Appl. Phys. 42194012

[44] Koelman P, Heijkers S, Tadayon Mousavi S, Graef W, Mihailova D, Kozak T, Bogaerts A and van Dijk J 2017 Plasma Process. Polym. 141600155

[45] SIGLO database, www.lxcat.net, accessed 20 March 2018

[46] Hagelaar G J M and Pitchford L C 2005 Plasma Sources Sci. Technol. 14 722-33

[47] Capitelli M, Ferreira C M, Gordiets B F and Osipov A I 2000 Plasma Kinetics in Atmospheric Gases (Springer Series on Atomic, Optical, and Plasma Physics vol 31) (Berlin: Springer)

[48] Phelps database, www.lxcat.net, accessed 5 September 2018

[49] Nie L, Chang L, Xian Y and Lu X 2016 Phys. Plasmas 23 093518

[50] van der Schans M 2018 Experiments on the physics of pulsed plasma jets $P h D$ thesis Eindhoven University of Technology

[51] Nijdam S, Takahashi E, Markosyan A H and Ebert U 2014 Plasma Sources Sci. Technol. 23025008 